\title{
EXPERIÊNCIAS DE ENSINO, PESQUISA E EXTENSÃO NO SETOR DE PEDAGOGIA DO HIJG
}

\author{
Terezinha Maria Cardoso
}

\begin{abstract}
RESUMO: Este artigo objetiva discutir a experiência de projeto de extensão e de estágio curricular obrigatório da última fase do Curso de Pedagogia (CED/UFSC), nas habilitações de Orientação Educacional e Supervisão Escolar, desenvolvido junto ao Setor de Pedagogia do Hospital Infantil Joana de Gusmão (HIJ). Tal experiência, desde o ano de 2000, tem trazido resultados positivos tanto para o trabalho do hospital como para a formação de novos pedagogos. Estágio curricular e extensão universitária se entrelaçam, atendendo as exigências de formação universitária, ao mesmo tempo em que fornecem assessoria e efetivo trabalho para a comunidade. Destaca-se a organização da classe hospitalar de $5^{\mathrm{a}}$ a $8^{\mathrm{a}}$ série para atender alunos/pacientes internados no HIJG e a produção de materiais informativos sobre o trabalho da classe hospitalar como os principais resultados desse estudo.
\end{abstract}

Palavras-chave: Classe hospitalar. Extensão universitária. Estágio curricular.

\section{EXPERIENCES OF TEACHING, RESEARCH AND EXTENSION AT THE HIJG PEDAGOGY DEPARTMENT}

ABSTRACT: The goal of this article is to discuss the experiences with the extension project and the curricular practice (training period) in the last stage of the Pedagogy Course (CED/UFSC), in the School Counseling and School Supervision graduation courses. This experience was developed with the Pedagogy department of the Joana de Gusmão Children's Hospital (Hospital Infantil Joana de Gusmão-HIJG). It has been having positive results since 2000, both for the hospital work and for the education of new Pedagogy academics. The Curricular practice (training period) and the academic

Doutora em Educação e professora do Centro de Educação e Pós-Graduação em Educação da Universidade Federal de Santa Catarina (UFSC).E-mail: tmaria@ced.ufsc.br 
extension get entwined to answer the academic education demands and, at the same time, provide the community with assistance and effective work. This text focuses on the organization of the Hospital Class from the $5^{\text {th }}$ to the $8^{\text {th }}$ grade to assist hospitalized students/patients at the Joana de Gusmão Children's Hospital and on the production of informative material about the hospital class work as the main results of this study.

Key words: Hospital school. Academic extension. Curricular practice (training period).

\section{A perspectiva da pesquisa e da extensão na organização dos estágios}

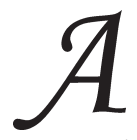

relação entre a universidade e os campos de estágio, principalmente no que se refere ao campo de conhecimento das licenciaturas, entre elas a Pedagogia, pode ser definida com as expressões: tênue, complexa, delicada.

Esses termos podem ser compreendidos em vista da complexidade dos sentidos e significados atribuídos à universidade. De modo geral, lhe é conferido o papel de produtora de saberes que, uma vez aplicados, mudariam para melhor a realidade das instituiçôes educacionais e da educação. E isso é tão verdade que, até bem pouco tempo, os estágios e práticas de ensino aconteciam no último semestre do curso, justamente por essa idéia de um conhecimento aprendido e formulado na universidade e que pode ser aplicado. Os campos de estágio nos cobram essa "aplicação", essa intervenção com resultados visíveis e, na medida em que eles não aparecem, sentem-se "usados". Esse sentimento gera resistências.

De sua parte, as instituições campo de estágio sentem-se agredidas por nossa empáfia de professores-pesquisadores-produtores de verdades. Nosso olhar e, por decorrência, o olhar de nossos estudantes têm como princípio focal a "pedagogia do fracasso", a crítica (muitas vezes com razão) contundente, porém desqualificadora das ações empreendidas naquele espaço. Quando olhamos as instituições, visualizamos o que elas têm de feio, de mal-feito, de fracasso, de erros e esquecemos de voltar nosso holofote para o que têm de bonito, de bem-feito, de sucesso.

Desde que ingressei como docente no CED/UFSC, foram poucos os semestres em que não trabalhei com estágios. A dificuldade em conseguir campos de estágio para os alunos levou-nos ${ }^{1}$ a repensar a forma de realizá-los. 
Assim, em 1993 formulamos a perspectiva do estágio como pesquisa e extensão. Nossa expectativa desde aquela época era a formação de um pedagogo com um olhar pesquisador, que delimitasse um problema e organizasse um projeto de investigação e ação. A problemática era proposta pelo campo. O professor supervisor passaria a ter aquele campo, durante o desenvolvimento do estágio, como foco de extensão, dedicando quatro horas semanais para discussão com a equipe pedagógica. Ao final do estágio, organizávamos seminários de socialização com a presença do campo. Tivemos sucessos e fracassos. Colhemos frutos acadêmicos. Percebemos os limites. Destaco dois:

1) A dificuldade, quase impossibilidade, de acompanhar com qualidade teórico-prática o número elevado de equipes, instituições e problemáticas.

2) A falta de continuidade das atividades em um dado campo. Os alunos, por questôes diversas (proximidades, afinidades na formação dos grupos, dificuldades de locomoção quando a escola era distante), nem sempre optavam pelas mesmas instituições nas quais já haviam realizado estágio no semestre anterior.

A renovação do quadro de docentes na Universidade e o empenho na formação em nível de doutorado revigoraram teorias e práticas. $\mathrm{O}$ estágio não ficou imune. As novas demandas dos alunos e das instituições educacionais, a abertura de novas frentes de atuação para o pedagogo, aliadas às orientações teórico-práticas dos professores supervisores, e a capacidade para atender diferentes frentes de trabalho efetivaram uma nova organização dos estágios, na qual a perspectiva da extensão se fortaleceu.

Os estágios passaram a ter uma organização que privilegia o vínculo do professor supervisor com a temática e com o campo. Assim, ao início da sétima fase do Curso de Pedagogia, na disciplina "Estágio Supervisionado I", os professores da área que podem e que desejam oferecer estágio se apresentam aos alunos, destacando as temáticas, os campos e as possibilidades (quantos grupos, com quantos membros, que campo/s). Dessa forma, os estágios fortalecem a extensão do docente, os estudantes aproveitam melhor as experiências teórico-metodológicas do professor, aumentam as chances de resultados concretos e com qualidade. Nesse texto pretendo refletir sobre a inserção com estágios e extensão no Hospital Infantil Joana de Gusmão. ${ }^{2}$ 
Essas experiências nos têm mostrado que há perspectivas de ganhos para todos os envolvidos. Vem se comprovando uma ótima perspectiva de modificar algumas das expressóes utilizadas para ilustrar definições para a relação entre a Universidade e o campo de estágio: ainda complexa e delicada, como são todas as relaçóes que envolvem pessoas, porém forte, corajosa, interdependente.

A perspectiva de extensão que trago neste texto não se refere a um modelo que o professor constrói na universidade e estende à comunidade. Antes, se refere a uma "escuta pedagógica" (Ceccim, 1997) e uma "escuta sensível” (Sousa, s/d) das necessidades apontadas pela comunidade à universidade, à qual o professor irá dispor seus conhecimentos teórico-práticos a serviço de um processo de reflexão-ação junto aos estudantes e a instituição, buscando encaminhamentos que resultem em dividendos para todos.

\section{O trabalho junto ao Setor de Pedagogia do Hospital Infantil Joana de Gusmão}

O Hospital Infantil Joana de Gusmão (HIJG) atua com essa denominação desde 1979, como pólo de referência no estado de Santa Catarina, no atendimento à saúde de crianças e adolescentes. Atende todas as regiōes do estado, nas patologias de maior complexidade, com unidades especializadas em cardiologia, cirurgia (pediátrica geral, plástica, oftalmologia, ortopedia, otorrinolaringologia, urologia), desnutrição, gastroenterologia, nefrologia, neurocirurgia, neurologia, oncologia, queimadura, pneumologia e terapia intensiva.

O Setor de Pedagogia do HIJG atualmente desenvolve cinco programas distintos. São eles: apoio pedagógico à criança internada: atendimento nas unidades viabilizando a interação entre o hospital e a escola de origem; estimulação essencial: para crianças de 0 a 6 anos com atraso no desenvolvimento neuropsicomotor; recreação: oportuniza o brincar como proposta terapêutica, possibilitando, por meio de brinquedo e brincadeiras, re-elaborar as manifestações de alegria e do lazer, resgatando a vitalidade e a autoconfiança; ambulatório-triagem: diagnóstico, orientação e acompanhamento escolar para crianças com atraso no desenvolvimento neuropsicomotor e com dificuldades na aprendizagem; 
classe hospitalar: continuidade da escolaridade formal, mantendo a sistematização da aprendizagem, promovendo o desenvolvimento e contribuindo para a reintegração à escola após a alta hospitalar. ${ }^{3}$

Classe hospitalar é a terminologia utilizada pelo Ministério de Educação/Secretaria de Educação Especial (MEC/SEESP) para designar o atendimento pedagógico educacional no hospital, com vistas à continuidade do aprendizado de conteúdos curriculares. Seu principal objetivo é atuar no combate ao fracasso escolar, comum às crianças e adolescentes que são submetidos a internações longas e/ou freqüentes, impossibilitando-os de acompanhar o ano letivo da escola regular (Brasil, 2002).

A literatura da área traz outras denominações, tais como: atendimento pedagógico-educacional hospitalar (Fonseca, 1999); espaço escolar para crianças hospitalizadas, atendimento escolar no ambiente hospitalar (Fonseca, 2002); escola hospitalar (Fonseca, 2003); escolarização hospitalar, espaço de ensino em ambiência hospitalar (Ortiz \& Freitas, 2001).

Neste artigo, utilizaremos a expressão classe hospitalar ou apenas classe, em vista de ser esta a nomenclatura utilizada pela Secretaria Estadual de Educação, na Portaria que regulamentou a implantação desse serviço nos hospitais catarinenses.

O direito ao atendimento educacional para crianças e adolescentes hospitalizados tem legitimidade e está previsto na Política Nacional de Educação Especial de 1994 e assegurado pela Resolução n. 41, de 1995, que além de tratar dos Direitos das Crianças e Adolescentes Hospitalizados reafirma o direito ao acompanhamento educacional curricular no período de internação. Soma-se a esses documentos a Lei de Diretrizes e Bases da Educação Nacional (n. 9.394/96). Em dezembro de 2002, foi lançado pelo Ministério da Educação, através da Secretaria de Educação Especial, documento fixando estratégias e orientações para organização do atendimento educacional domiciliar e nas classes hospitalares, forma como se denomina o trabalho pedagógico no âmbito hospitalar.

Fonseca (1999), em pesquisa de levantamento da situação brasileira do atendimento pedagógico-hospitalar, traz como resultado um total de 30 classes, a maioria delas fundada a partir da década de 80 do século passado. Antes desse período, apenas quatro classes funcionavam 
em território nacional. A pesquisa foi reeditada (Fonseca, 2002), evidenciando uma ampliação para 74 classes hospitalares. Os resultados trazidos pela autora apontam para um "boom" na criação de classes na década de 90 do século passado e nos dois primeiros anos deste século.

A ampliação do atendimento educacional-hospitalar se deu como resposta às legislações propostas na década de 1990. Em Santa Catarina, esse quadro se confirma. As primeiras classes hospitalares do estado foram fundadas em convênio com a Secretaria Estadual de Educação e do Desporto (SED): uma em Florianópolis, no Hospital Infantil Joana de Gusmão (HIJG), em setembro de 1999, outra em Lages, no Hospital Infantil Seara do Bem, em 2000. A Portaria n. 30 da SED, de 5 de março de 2001, que dispóe sobre a implantação de atendimento educacional na classe hospitalar para crianças e adolescentes matriculados na pré-escola e no ensino fundamental, internados em hospitais, vem regulamentar esse atendimento no âmbito do estado de Santa Catarina. Cada classe hospitalar é filiada a uma unidade de ensino da Rede Estadual, que dá amparo legal ao trabalho. Os dados da SED apontam para a existência de 12 classes hospitalares no estado, a maioria criada no ano de 2002, duas implementadas em 2001 e uma em 2003.

\section{Fazendo estágios e extensão no HIJG}

A perspectiva de extensão junto ao Setor de Pedagogia do HIJG teve início em 2001, com o interesse de duas estudantes da $7^{\text {a }}$ fase do Curso de Pedagogia, cuja formação anterior (uma delas técnica em enfermagem) as instigava a desenvolver o estágio de modo a conciliar educação e saúde. Experiências vividas no período em que estive afastada para cursar o doutorado em Educação levaram-me a encampar o desejo das estudantes e procurar o HIJG para solicitar estágio no Setor de Pedagogia.

Contudo, para a abertura do campo para estágios do Curso de Pedagogia, me foi solicitada uma contrapartida, qual seja: um trabalho de extensão assessorando a organização de uma classe hospitalar de $5^{\text {a }}$ a $8^{a}$ série. $O$ combinado foi que esse trabalho seria realizado em conjunto com os estágios curriculares obrigatórios do Curso de Pedagogia. O campo foi aberto e as estudantes realizaram estágio no ambulatório de dificuldade de aprendizagem, além de terem experienciado o trabalho na classe hospitalar de $1^{\mathrm{a}}$ a $4^{\mathrm{a}}$ série. Esse primeiro grupo realizou 
estágio, efetuando estudo de caso de uma estudante das séries iniciais que freqüentava o ambulatório. Denomino esse estágio como um tempo de reconhecimento e afinação de condutas junto ao campo. A partir dele, os trabalhos de extensão e de estágios foram desenvolvidos.

\section{Assessorando a organização da classe hospitalar de $5^{\mathrm{a}}$ a $8^{\mathrm{a}}$ série}

De modo a atender a solicitação do campo, os grupos de estagiárias nos anos de 2002 e 2003 tiveram como temática para o trabalho do estágio a organização da classe de $5^{\mathrm{a}}$ a $8^{\mathrm{a}}$ série. Com o primeiro grupo efetivamos estudo das possibilidades e viabilidade de tal projeto. Para tanto, foram realizadas atividades como: pesquisa na Internet, procurando conhecer experiências nesse nível de ensino no ambiente hospitalar; discussões com professores de metodologia e didática do Curso de Pedagogia; entrevistas com profissionais da educação sobre como pensariam uma classe hospitalar de $5^{\mathrm{a}}$ a $8^{\mathrm{a}}$ série, tendo em vista as peculiaridades de rotatividade dos alunos, entre outras; visita e entrevista à classe hospitalar na região do Alto Vale de Santa Catarina, a qual informou que trabalhava com todas as séries do ensino fundamental; realização de oficinas com adolescentes internados no hospital, buscando elementos mais concretos para a organização da classe. Ao final desse estágio, nossa equipe e a coordenadora do Setor de Pedagogia do HIJ sabíamos que o trabalho pedagógico deveria envolver arte e que poderia ser desenvolvido na forma de oficinas. Tínhamos também algumas incertezas: a classe deveria ser organizada por série, classes de $5^{\mathrm{a}}$ e $6^{\mathrm{a}}$ séries e classes de $7^{\mathrm{a}}$ a $8^{\mathrm{a}},{ }^{4}$ ou com todas as séries juntas? As classes deveriam ter como princípio a co-educação ou deveríamos formar turmas de meninos separados das meninas? Essas questões se originaram das dificuldades de comunicação entre os educandos, observadas nas oficinas.

O segundo grupo organizou e implementou a classe hospitalar de $5^{a}$ a $8^{a}$ série. O Hospital Infantil cedeu um espaço para o funcionamento da classe e foram angariados no próprio local, por meio de doações: mobiliários, computadores e material didático. As estagiárias trataram de transformá-lo em um ambiente aprazível e que lembrasse uma sala de aula. Além disso, realizaram levantamento entre aos adolescentes internados (com idades entre 11 e 15 anos) sobre os temas de interesse para o trabalho na classe. As entrevistas evidenciaram expectativas dos educandos com relação à possibilidade de estudar e não 
perder o ano letivo. Levando em conta esse desejo, organizaram-se oficinas com temas transversais (sexualidade, paz, drogas, sistema solar e vida extraterrestre). $\mathrm{O}$ trabalho com oficinas possibilitou uma atuação mais efetiva por parte dos educando, criando um processo de aprendizagem mais dinâmico, criativo e agradável. Por outro lado, na oficina, uma temática foi trabalhada em um curto período de tempo, o que atendia a problemática de rotatividade dos estudantes, particularidade da classe hospitalar.

O próximo passo para a organização da classe foi a contratação de professores das metodologias e práticas de ensino dos cursos de Licenciatura da UFSC, buscando apoio para a continuidade das atividades, o que se deu também com a atuação de estagiários. Desse modo, as oficinas realizadas pelas estudantes de Pedagogia foram observadas pelas primeiras estagiárias do Curso de Licenciatura em Ciências Biológicas. A gestão da coordenação junto à Secretaria de Educação objetivou a contratação de duas professoras, que passaram a atuar já no segundo semestre de 2003: uma efetiva ( 40 horas) na área de Língua Portuguesa e outra substituta (20 horas) na área de Ciências. Atualmente, a substituta contratada atende na área de Matemática.

O contato com colegas do Departamento de Metodologia de Ensino, do Centro de Educação da UFSC, resultou na formação de um grupo voltado ao ensino, pesquisa e extensão, com projeto de extensão "Articulando uma classe hospitalar de $5^{\mathrm{a}}$ a $8^{\mathrm{a}}$ séries: ensino e produção de conhecimento com vistas ao atendimento de jovens estudantes hospitalizados em Santa Catarina”, financiado pelo PROEXTENSÁO; projeto de pesquisa "Convergindo olhares para alunos hospitalizados: conteúdos, metodologias e práticas", com apoio financeiro da FAPESC, bolsas de extensão, de iniciação científica e de estágio nos campos de conhecimento: Ensino de Língua Inglesa, Ciências, Educação Física e Pedagogia. Com as verbas arrecadadas foi equipada uma sala no HIJG para a classe de $5^{\mathrm{a}}$ a $8^{\mathrm{a}}$, mantendo, junto às professoras permanentes (Português e Matemática), estagiários nas outras áreas de ensino. Esses estudantes organizaram o Manual de Estágio no Hospital Infantil.

\section{Estudando a relação entre classe hospitalar e escola regular}

Tendo realizado o trabalho de organização e implementação da classe hospitalar de $5^{\mathrm{a}}$ a $8^{\mathrm{a}}$ série, o Setor de Pedagogia solicitou que os 
estágios de Pedagogia se voltassem para a realização de estudos de caso, buscando entender a relação entre a classe hospitalar (de $1^{\mathrm{a}}$ a $4^{\mathrm{a}}$ série) e a escola de origem dos estudantes. Faz parte da rotina do trabalho na classe o envio de relatórios (via correio) para as escolas de origem dos educandos após a alta, desde que este a tenha freqüentado por mais de três dias. Nesse relatório constam registros diários a respeito do que foi trabalhado e do envolvimento do educando, bem como uma solicitação de avaliação por parte da escola sobre o trabalho desenvolvido ter ou não facilitado a reintegração do educando no contexto escolar. Trabalharam nessa temática outros dois grupos de estagiárias (2004 e 2005).

O primeiro grupo (2004) teve como objetivos investigar a relação entre as atividades pedagógicas educacionais da classe hospitalar e o desempenho dessas crianças e adolescentes em sua escola regular após a alta; verificar os impedimentos, por parte da escola, de devolver a avaliação solicitada pelo HIJG; inquirir sobre o processo de re-inserção da criança no retorno à classe regular e sobre os encaminhamentos realizados para este fim; averiguar como os conteúdos trabalhados na classe hospitalar contribuíram para a re-inserção da criança na classe regular.

Para atender a esses objetivos, foi realizado levantamento no banco de dados do Setor de Pedagogia para identificar escolas que possuíam crianças com doenças crônicas, com mais de uma passagem pela classe hospitalar, e com maior número de casos de internação e atendimentos na classe. De posse desses dados, foram selecionadas seis escolas da Grande Florianópolis e da Capital, as quais foram inquiridas (direção, equipe pedagógica e professores das crianças). Estes profissionais foram questionados sobre o conhecimento que possuíam da existência da classe hospitalar no Hospital Infantil e do trabalho ali desenvolvido; se receberam e tomaram conhecimento do relatório enviado pela classe; como se deu o retorno e a re-inserção da criança após a alta hospitalar.

Com esse estudo, percebemos o profundo desconhecimento por parte das escolas do trabalho pedagógico realizado no interior do HIJG as escolas com estudantes internados passaram a ter conhecimento da existência da classe hospitalar a partir do relatório recebido. Contudo, a multiplicidade de atividades, tarefas e acontecimentos no cotidiano da escola parece que a impede de ler com a devida atenção o relatório e muitas delas desconheciam a solicitação de retorno. Houve caso da escola procurar o relatório e só então, admirada, conhecer o trabalho que foi 
Experiências de ensino, pesquisa e extensão no Setor de Pedagogia do HIJG

desenvolvido com seu estudante no período de internação. Os profissionais da escola acreditavam que no relatório constavam apenas dados sobre a saúde do educando. Depois de lerem o documento, observaram que os registros eram muito mais amplos. Outro dado importante foi a constataçẫo de que a alta hospitalar nem sempre coincide com a alta médica e, por vezes, o relatório chega na escola e a criança ainda permanece em casa por um longo período e, sem a criança, a escola não consegue avaliar o trabalho desenvolvido na classe. Também se observou que não é realizado, por parte da escola, trabalho com a criança e/ou com a turma no retorno desta. No caso de doenças crônicas a literatura tem mostrado a necessidade de atividades que facilitem a reintegração do educando à escola, dadas as dificuldades específicas (dores, queda de cabelo, vômitos, diarréia, dietas especiais, horários de remédios, entre outros) originadas pelo tratamento à doença (Valle, 2001; Nucci, 2002).

Com esse grupo de estagiárias ficou evidente a necessidade de um maior intercâmbio e de políticas de formação e de informação às escolas com relação ao atendimento educacional hospitalar e a necessidade de trabalho específico para receber os educandos com doenças crônicas, geralmente vítimas de preconceito por parte de colegas e de professores. $\mathrm{O}$ relatório não é o bastante.

Em vista disso, um outro grupo de estagiárias trabalhou com essa temática, acompanhando uma criança do Centro Integrado de Oncologia Pediátrica, com histórico de afastamento da escola, para verificar como ocorria o trabalho junto à turma e ao aluno acometido por doença após o retorno para a escola. Para tanto, foram realizadas as seguintes atividades: entrevistas com professores e diretor da escola, para verificar se possuíam conhecimento acerca da existência da classe hospitalar e colher dados de como a escola trabalha com um estudante que passou pela classe. Foram realizadas também entrevistas com mãe de aluno para ouvir sua opinião acerca da classe e para obter autorização para acompanhá-lo; entrevista com a criança para obter suas impressōes sobre a sua relação com a classe hospitalar e, finalmente, contribuir sempre que necessário com as tarefas pedagógicas. Além das entrevistas, foram feitas observações das dinâmicas do trabalho na turma da criança. Também nesse caso, não foram observados o desenvolvimento de atividades voltadas à reintegração da criança e os preconceitos que ocorrem quando as crianças retornam e são acompanhadas na mesma turma. 
Ao mesmo tempo em que aprofundava o estudo da temática, o grupo de estagiárias organizou materiais de informação (cartazes e folders) para distribuir nas escolas, a fim de que conheçam e se motivem a acompanhar o trabalho realizado nas classes do HIJG. Esse trabalho não tem resultados visíveis. A médio e longo prazos é que saberemos o alcance deles no reconhecimento pelas instituiçóes escolares do trabalho desenvolvido no HIJG. A continuidade e aprofundamento da temática estão se dando por meio de orientação de trabalho de mestrado em Educação.

\section{Desenvolvendo materiais informativos para escolas com alunos com câncer}

Atualmente estamos dando continuidade ao trabalho de desenvolvimento de materiais informativos para as escolas, agora junto ao atendimento educacional efetivado no ambulatório de oncologia do hospital. O objetivo dos projetos é a construção de material didáticopedagógico para trabalhar com as escolas, professores e estudantes colegas de pacientes com câncer.

De acordo com a Associação Brasileira de Linfoma e Leucemia (ABRALE), a continuidade escolar pode falhar sob diversos aspectos, ao depender de pessoas de diferentes áreas, assim como de instituições que lidam diretamente com a criança com câncer. A boa relação e a troca de informações entre família, escola e hospital são extremamente necessárias nesses casos. Devido às suas próprias limitações, o hospital não tem acesso ao que ocorre com a criança fora do ambiente hospitalar e, por isso, precisa do apoio da professora, dos pais e da própria criança para conseguir fazer com que seus pacientes não tenham prejuízo escolar devido ao tratamento de câncer.

Nesse sentido, em 2006, um grupo de estagiárias coligiu subsídios com vistas à organização de uma cartilha a ser enviada às escolas que atendem crianças com câncer. Foram realizadas visitas e entrevistas com professores e equipe pedagógica e administrativa de três escolas da Grande Florianópolis, com o intuído de identificar as principais dificuldades, barreiras e receios dos profissionais da educação frente à situação de atender uma criança com diagnóstico de câncer e em tratamento. Ao mesmo tempo, o grupo buscou descobrir, junto às crianças 
- acometidas pelo câncer e que freqüientam aquelas escolas - e suas famílias, quais eram as preocupações com relação à permanência das mesmas na escola. Para uma maior compreensão do câncer infantil, foram organizados encontros de estudo no HIJG, para leitura e debate de textos, acadêmicos e informativos, produzidos sobre a temática.

Em 2007, um novo grupo deu continuidade ao trabalho e está desenvolvendo material audiovisual, com base no relatório do grupo anterior e em entrevistas com a equipe médica e de enfermagem. Esse trabalho está no início e a expectativa nossa e do HIJG é grande.

\section{Conclusões}

À guisa de conclusão, reporto-me a Leonardo Boff (1999), que traz o cuidado como uma ética do humano, sublinhando que:

O que se opõe ao descuido e ao descaso é o cuidado. Cuidar é mais do que um ato; é uma atitude. Portanto, abrange mais do que um momento de atenção, de zelo e de desvelo. Representa uma atitude de ocupação, preocupação, de responsabilização e de envolvimento afetivo com o outro (Boff, 1999, p. 33)

Ao escolher o Setor de Pedagogia do Hospital Infantil Joana de Gusmão como lugar de formação de alunas estagiárias do Curso de Pedagogia, busco essa ética do humano, como propóe o autor, entendendo-a como pedra angular da formação docente, seja ele orientador, supervisor ou professor. Acredito que essa ética pode ser experienciada pelos estudantes, ao viverem a realidade do atendimento educacional efetivado no interior de hospitais e se encontrarem com a alegria das crianças que, embora doentes - o que as qualificaria a não freqüentar a escola -, buscam a classe hospitalar como lugar de sociabilidade, de encontro com o outro, de alegria. E, porque não dizer, um refúgio que as faz, se não esquecer, pelo menos viver outras experiências que não as relativas ao adoecimento, com o afastamento de seu contexto familiar e de socialização/sociabilidade, à doença que a acomete e aos procedimentos hospitalares sempre tão dolorosos.

A atenção integral à vida (Ceccim, 1997) requer uma pedagogia em cuja práxis o sentir é o princípio de vida. Nesse sentido, Sousa (s/ d) sugere que troquemos o pressuposto cartesiano do penso, logo existo 
por outra lógica, a do sinto, por isso vivo, sublinhando que "é porque sinto que posso conhecer, então, atribuir significados, configurar o que vivencio como linguagem, transformar em teoria, construir argumentos que expliquem" (Sousa, s/d, p. 13).

Enfim, acredito que, ao articular o estágio curricular à atividade de extensão, adotando um campo, como professora da Universidade, a um só tempo sou formadora de futuros profissionais da educação e presto serviço, realizando um trabalho de formação continua e devolvendo à instituição resultados de ações práticas efetivadas junto com os estagiários.

Recebido em abril de 2007 e aprovado em outubro de 2007.

\section{Notas}

1. Foi co-participante dessa proposta de estágio a professora Olga Celestina da Silva Durand.

2. Além do Hospital Infantil Joana de Gusmão, hoje são oferecidos diferentes campos de estágio/extensão, conforme a área de trabalho e de aprofundamento teórico-metodológico do professor: empresas, ONGs, instituiçôes como a Cidade da Criança, Escolas em Favelas, Escolas da Rede Municipal e Estadual de Ensino, Educação de Jovens e Adultos, entre outras.

3. Disponível em: <http://www.saude.sc.gov.br/hijg>.

4. Pensávamos assim atender às diferenças de interesses e de idades.

\section{Referências bibliográficas}

BOFF, L. Saber cuidar: ética do humano - compaixão pela terra. Petrópolis: Vozes, 1999.

BRASIL. Ministério da Educação. Secretaria de Educação Especial. Classe hospitalar e atendimento pedagógico domiciliar: estratégias e orientações. Brasília, DF: MEC/SEESP, 2002.

CECCIM, R.B. Criança hospitalizada: a atenção integral como uma escuta à vida. In: Ceccim, R.B.; Carvalho, P.R.A. (Org.). Criança hospitalizada: atenção integral como escuta à vida. Porto Alegre: UFRGS, 1997.

FONSECA, E.S. A situação brasileira do atendimento pedagógico-educacional hospitalar. Educação \& Pesquisa, São Paulo, v. 25, n. 1, p. $117-$ 129, jan./jun. 1999. 
FONSECA, E.S. Implantação e implementação de espaço escolar para crianças hospitalizadas. Revista Brasileira de Educação Especial, Marília, v. 8, n. 2, p. 205-222, jul./dez. 2002.

FONSECA, E.S. Atendimento escolar no ambiente hospitalar. São Paulo: Memnon, 2003.

NUCCI, N.A.G. A criança com leucemia na escola. Campinas: Livro Pleno, 2002.

ORTIZ, L.C.M.; FREITAS, S.N. Classe hospitalar: um olhar sobre sua práxis educacional. Revista Brasileira de Estudos Pedagógicos, Brasília, DF, v. 82, n. 2000/2002, p. 70-77, jan./dez. 2001.

SOUSA, A.M.B. Educação biocêntrica: uma poética da cognição. Florianópolis, s/d. (Trabalho não publicado).

VALLE, E.R.M. (Org.). Psico-oncologia pediátrica. São Paulo: Casa do Psicólogo, 2001. 